\title{
Guest Editorial: Special Section-Egress and Human Behavior in Fire
}

\author{
Rita F. Fahy*, Fire Data Bases and Systems, Fire Analysis \& Research \\ Division, National Fire Protection Association, 1 Batterymarch Park, \\ Quincy, MA 02169, USA
}

In recent years, NIST has made a strong commitment to research in the area of building egress, and this special issue highlights findings from some of the major projects they've undertaken lately.

Three of the papers are based on NIST's study of the evacuation of the World Trade Center on September 11, 2001. The first of the three focuses on occupants' accounts of their experience, gleaned from interviews and surveys (Averill, Peacock and Kuligowski). The second details the statistical analysis of that data, and provides some understanding of the issues that slowed or enhanced the evacuation that day (Peacock, Averill and Kuligowski). And the third describes the computer modeling of the evacuation, including simulations that address various additional scenarios, such as full occupancy conditions and elevator usage, and provide context and help in understanding the actual evacuation (Kuligowski, Peacock and Averill).

The other two papers cover more general evacuation behavior topics. A paper by Gwynne describes a template for a proposed on-line database for storing evacuation and behavioral data from experiments and experience. The tool he describes will provide guidance to researchers in the data collection process and recording of data and will provide a valuable resource to users needing to access egress data sets. The second paper, by Kuligowski, discusses the need for improved prediction of occupant behavior in evacuation models that have tended to rely on simplifying assumptions. This would involve developing a comprehensive theory of behavior that could be embedded into evacuation models, thus improving estimates of evacuation times.

Special thanks go to Erica Kuligowski for assembling the papers included in this special issue!

\footnotetext{
* Correspondence should be addressed to: Rita F. Fahy, E-mail: rfahy@NFPA.org
} 